Tahani A Al-Sandook BDS, PhD (Prof.)

Ziad H Delemi BDS, FIBMS MF (Lec.)

Baydaa A Al-Rawi BDS, MSc. (Lec.)

\section{Oral and Rectal Sedation with Diazepam for Uncooperative Child during Dental Procedure}

Dept of Oral and Maxillofacial Surgery

College of Dentistry, University of Mosul

Dept of Oral and Maxillofacial Surgery

College of Dentistry, University of Mosul

Dept of Pedodontics and Preventive Dentistry College of Dentistry, University of Baghdad

\footnotetext{
الخحلاصة

الأهداف: تمدف الدراسة الى مقارنة فعالية الدايازيبام كمسكن بوعي تام للأطفال غير المتجاوبين و يحتاجون إلى مختلف العلاجات في طب الأسنان عند إعطائه فمويا

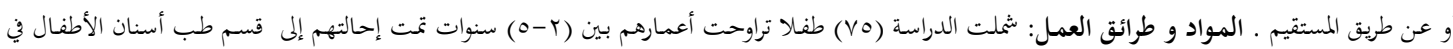

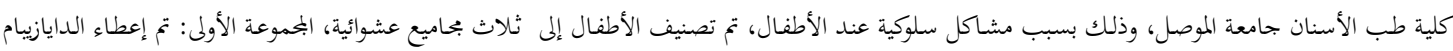

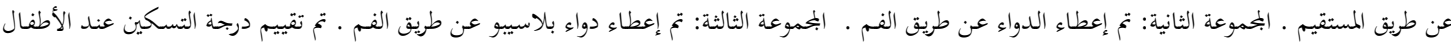

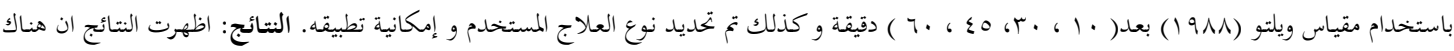

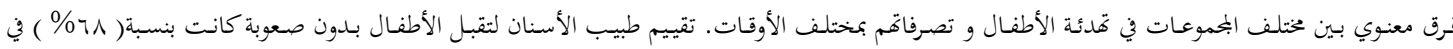

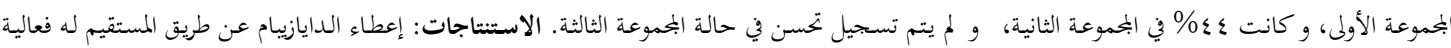

واضحة في تدئة الأطفال و تسكينهم عند استطباب الأسنان.
}

\begin{abstract}
Aims: To identify the clinical picture and the association between dry socket and severe postoperative development with one of the systemic risk factors (typhoid fever). Materials and Methods: Twenty adult (both sexes) patients attended dental clinic searching for different dental treatments were studied. The clinical picture of 6 months period study was evaluated by completing two case sheet forms. They were diagnosed having dry sockets and severe postoperative pain. Blood samples were taken for bacteriological, serological and hematological study to diagnose typhoid fever. These tests included WAT, WFT, WBCs and blood culture. Results: Significant correlation existed between postoperative pain and typhoid fever examined by $\mathrm{BC}$ and the highest percentage was with dry socket $(61.5 \%)$ followed by WFT $(57.1 \%$, WAT (44.4\%) using two tests for diagnosis showed that WFT and BC gave $97.9 \%$ positive for dry socket and Kappa test was $88 \%$, while WAT and WBCs or WFT and WAT gave the least non significant correlation. Conclusion: There was a strong correlation between dry socket and typhoid fever and the most sensitive tests for diagnosis was BC followed by WFT, WBCs and WAT.

Keywords: Typhoid fever, dry socket, postoperative pain
\end{abstract}

Al-Sandook TA, Delemi ZH, Al-Rawi BA. Oral and Rectal Sedation with Diazepam for Uncooperative Child during Dental Procedure. Al-Rafidain Dent J. 2012; 12(2): 321-328.

Received: 22/3/2011 Sent to Referees: 23/3/2011

Accepted for Publication: 8/6/2011

\section{INTRODUCTION}

When children are in need of dental treatment as a result of trauma or caries, the dentist has not usually had any opportunity to instill confidence in the patient ${ }^{(1)}$ and normally fear of the dentist is fairly common in children. ${ }^{(2)}$

When behavioral management methods such as tell-show-do, positive rein- forcement, controlled expectations, distraction, modeling and suggestion have failed to achieve treatment acceptance in uncooperative children, an addition of appropriate and targeted use of pharmacological agents have proved to be very helpful. ${ }^{(3)}$

Sedation was indicated in order to minimize motion artifact, facilitate 
successful completion of the procedure and potentially minimize risk to the patient. There are a variety of sedatives available. Most of the standard and most popular sedatives have been in existence for almost 100 years ${ }^{(4)}$

The pediatric dental literature contains numerous reports on various medications (e.g., nitrous oxide, opioids, benzodiazepines, chloral hydrate, barbiturates and antihistamines) which have been administrated alone or in combination. ${ }^{(5-9)}$

Diazepam has been used to manage an uncooperative child in a dental setting. It is a water insoluble benzodiazepine and requires the organic solvent propylene glycol to dissolve it. Propylene glycol is most likely responsible for renoirritation and thrombophebitis that may occur during injection. Diazepam undergoes metabolism to active desmethyl diazepam and oxazepam that can produce sedation $6-8$ hours after its initial administration ${ }^{(10)}$. Diazepam is sedative - hypnotic agent and act in the brain on specific receptors enhancing GABAergic transmission. Flumazenil can be used to reverse the sedative action of diazepam but repeated doses are needed ${ }^{(11)}$. Diazepam is very popular sedating agents due to its wide margin of safety and it has wide therapeutic index. It has many pharmacological effects which include: sedation, hypnosis, anesthesia, anticonvulsant effects, muscle relaxation and effects on respiration and cardiovascular function. It is indicated as hypnotic, in anxiety, tension, muscle spasm, psychosomatic and behaviour disorders, dysmenorrhoea, cerebral palsy, upper motor neuron spasticity, sedative for surgical procedures, labour, tetanus, eclampsia and epilepsy. Side effects include drowsiness, nausea, dizziness, blurred vision, headache, incontinence, slurred speech and skin rash. It is contraindicated for infants, patients with a history of convulsive disorders and patients with glaucoma ${ }^{(12)}$. Diazepam can be administrated orally, rectally or parenerally. It is rapidly absorbed from the gastrointestinal tract ${ }^{(13,14)}$. Drugs given in the rectum as the rectum promotes absorption of the medication because the rectum's wall is thin and its blood supply rich and it contains many capillaries and can produce a high drug concentration in the circulation ${ }^{(15,16)}$. Rectal administration avoids drug inactivation by stomach acid and digestive enzymes and about $50 \%$ of that absorbed bypasses the liver and goes directly into the systemic circulation. In some circumstances, it may be advantageous to administer a drug rectally, for example if a patient is unconscious or vomiting, or uncooperative in some way, but generally, it is considered an unpleasant method. ${ }^{(17)}$

\section{MATERIALS AND METHODS}

The subjects comprised 75 children aged $2-5$ years consecutively referred to the Department of Paediatric Dentistry, College of Dentistry, University of Mosul, because of behavioral management problems. Twenty five children were premedicated rectally and twenty five children were premedicated orally with diazepam, meanwhile twenty five children receive oral placepo of sugared syrup. Sedation with diazepam was recommended for uncooperative children or children with dental fear when they were in need to acute dental treatment because of pain. They were healthy without any systemic disease.

The children were seen for their initial exam it was determined that they definitely exhibited "definitely negative" behavior according to the Frankl scale ${ }^{(18)}$.

The subjects were randomly assigned to one of the three experimental groups and each group consisted of 25 children. Group I- received the diazepam rectally, group II received the diazepam orally and group III received placebo orally.

The children were allocated to receive diazepam in concentration of $0.7 \mathrm{mg} / \mathrm{kg}$ body weight according to Apozepam, Dumex - Alpharma, Helsingborg, Swe$\operatorname{den}^{(1)}$.

Children's body weights were measured using digital balance (Personal scale, China).

For group I, children received rectally the diazepam solution (Dialin Diazepam ampoules of $5 \mathrm{mg} / 2 \mathrm{ml}$, Ibn Hayyan Pharmaceuticals R. Faysal \& Co., Homs, Syria), after diluted with distilled water to promote perfect absorption., External creams should be applied directly on the rectal opening, using a gloved finger. Then 
the diluted diazepam solution should be administered with Mantour disposable syringe without needle (Asia Medical Instrument Corporation, UK) inserted $3-4$ $\mathrm{cm}$ carefully into the rectum. After administration of diazepam the buttocks should be apposed tightly for about two minutes to prevent loss of solution ${ }^{(19)}$.

Group II children received diazepam Syrup orally (Valiapam syrup, Ninevah Drug Industry, Ninehah, Iraq).

Group III children received $5 \mathrm{ml}$ of placebo syrup orally. The syrup was freshly prepared and consisted of glucose powder (The State Company for Drugs
Industry and Medical Appliances, Samarra, Iraq) dissolved in distilled water. After 10 minutes of diazepam administration, the local anesthetic agent was administrated to the patient and the dental treatment carried out according to the patient's need.

The following assessments were recorded by the dentist: ${ }^{(19)}$

- The child's level of sedation (state of mind) was assessed according to Wilto's sedation scale ${ }^{(20)}$ (Table 1) after 10 , 30,45 and 60 minutes.

Table (1): Level of sedation (state of mind) according to Wilton (1988)

\begin{tabular}{ll}
\hline Drowsy & Sitting or lying comfortably with tired or half - closed eyes, responds \\
& to minor stimulation \\
Calm & Sitting or lying comfortably with open eyes, relaxed \\
Alert & Not clinging to parent, may whimper but not cry \\
Agitated & Clinging to parent and / or crying \\
\hline
\end{tabular}

- The dental treatments: extraction, permanent filling, pulpotomy or pulpectomy.

- The feasibility of dental treatment: 1 . Treatment without any difficulty. 2 . Treatment with some difficulty and need of preventive holding from the parent. 3 . Treatment with extreme difficulty.

The estimated sedative drug - effect after one hour.

- Side effects or any complication or unusual behavior assumed to be related to the premedication as nausea, dizziness, headache or unusual behavior during the treatment.

The parents were asked to record the following assessments: ${ }^{(19)}$

- How did you experience the premedication of your child?

- Did your child show any unusual behavior on the day of treatment or on the following day?

- How long do you estimate that your child was effected by the drug?
- Could you tell me you impression of your child's memory of the treatment procedure?

Data were analyzed using numbers and percentages. Kruskal - Wallis test compared between the different groups to find if there is a significant difference on the sedation level and children behavior at different times. Crosstabulation and Pearson's chi - square were used to find if there is significantly affect between groups and treatments' acceptance. The level of significant set at $p \leq 0.05$.

\section{RESULTS}

Seventy five children were included in this study. The mean age of children was 3.2 years (range 2 years to 5 years).

For group I (Figure 1), 56\% of children were alert after 10 minutes, after 30 minutes $56 \%$ of children were calm and $8 \%$ were drowsy, after 45 minutes $64 \%$ were calm and $24 \%$ were drowsy, meanwhile after 60 minutes $48 \%$ were calm and $20 \%$ were drowsy. 


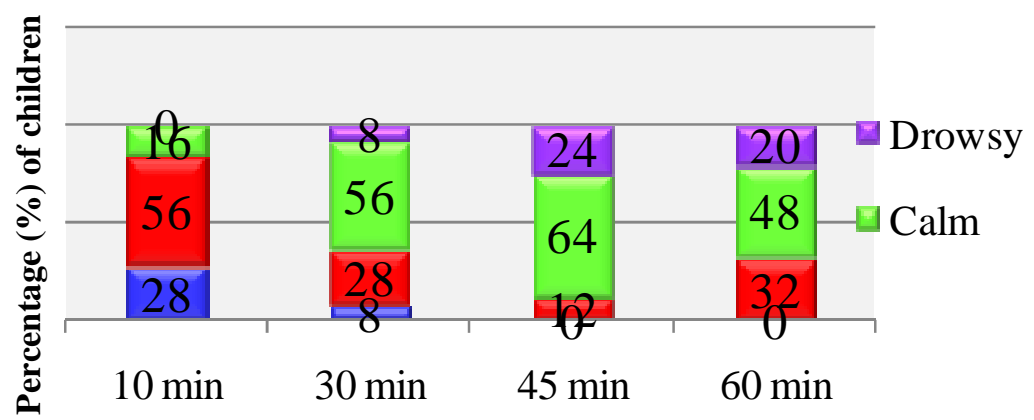

Figure (1): The sedative effect on children behavior assessed by the dentist after 10, 30, 45 and 60 minutes for rectally diazepam administration group

For group II (Figure 2), 60\% of children were agitated after 10 minutes, after 30 minutes $44 \%$ of children were agitated, $36 \%$ were alert and $20 \%$ were calm, after
45 minutes $40 \%$ were calm and $8 \%$ were drowsy, meanwhile after 60 minutes $56 \%$ were calm and $16 \%$ were drowsy.

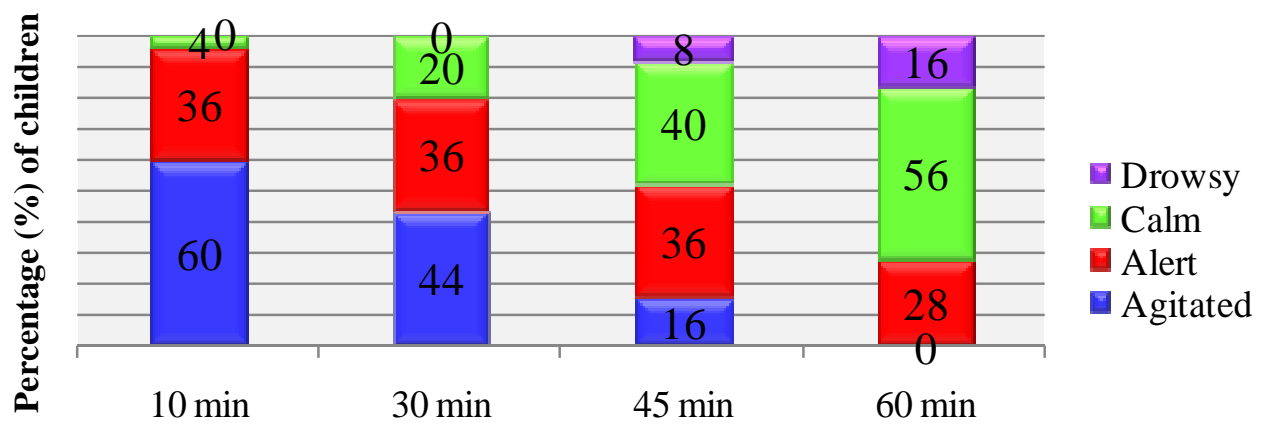

Figure (2): The sedative effect on children behavior assessed by the dentist after 10, 30, 45 and 60 minutes for orally diazepam administration group

For group III (Figure 3), 100\% of children were alert after 10 minutes, after 30 minutes $92 \%$ of children were agitated, $4 \%$ were alert and $4 \%$ were calm, after 45 minutes $88 \%$ were agitated, $8 \%$ were alert and $4 \%$ were calm, meanwhile after 60 minutes $92 \%$ were agitated and $8 \%$ were alert.

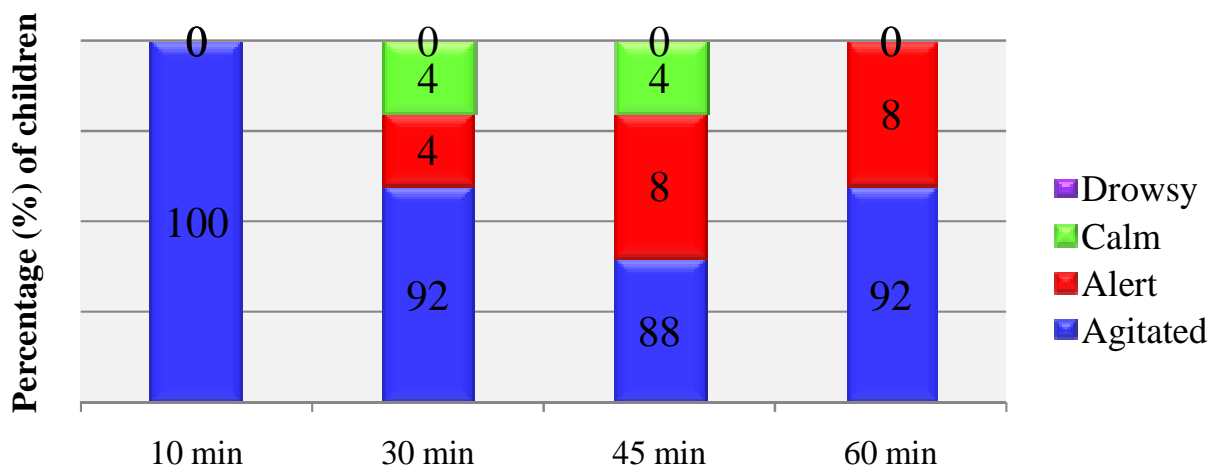

Figure (3): The sedative effect on children behavior assessed by the dentist after 10, 30, 45 and 60 minutes for placebo group 
Kruskal - Wallis Test (Table 2) demonstrated that there was significant difference at $p \leq 0.05$ between the three groups on the sedation level and children behavior after different times $(10,30,45$ and 60 minutes).

Table (2): Kruskal - Wallis Test compare between the different groups on the sedation level and children behavior at different times.

\begin{tabular}{ccccc}
\hline & After 10 min. & After 30 min. & After 45 min. & After 60 min. \\
\cline { 2 - 5 } Chi - square & 27.369 & 36.004 & 45.410 & 51.297 \\
df & 2 & 2 & 2 & 2 \\
$P$ - value* & 0.000 & 0.000 & 0.000 & 0.000 \\
\hline
\end{tabular}

*Significant difference at $P \leq 0.05$.

Of seventy five dental treatments after sedation, 25 procedures carried out for each group (Figure 4).

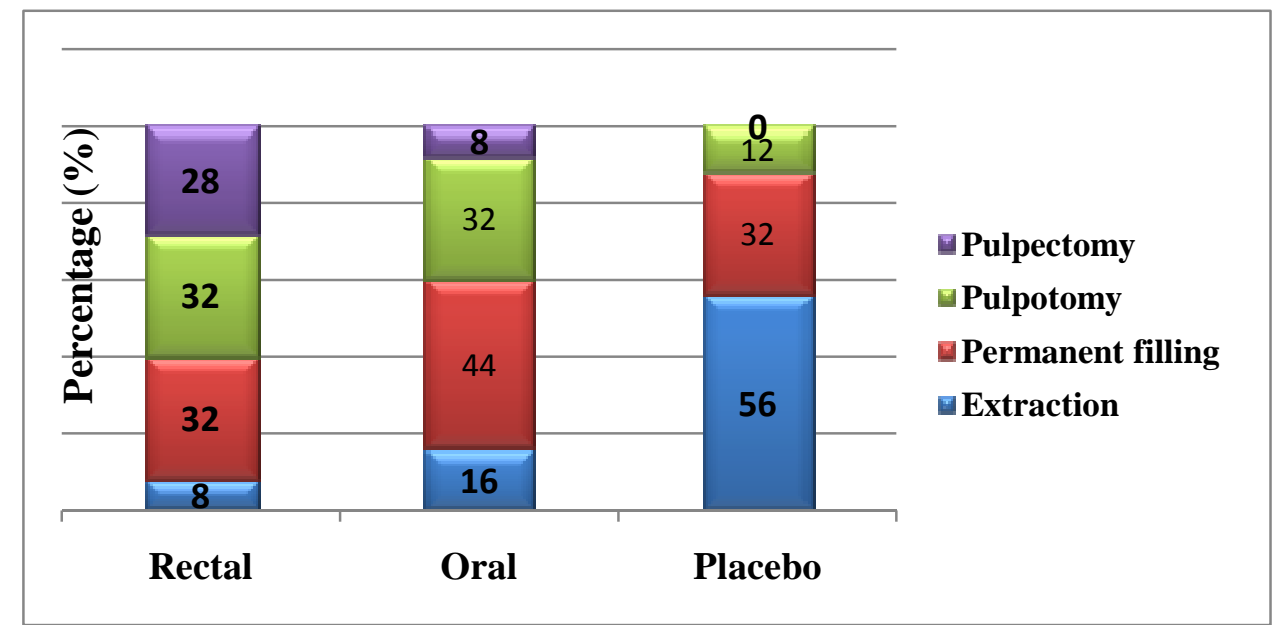

Figure (4): The percentage of each dental treatment carried out for rectally, orally and placebo groups.

For group I, the percentage of each dental treatment include: $28 \%$ puplectomy, $32 \%$ pulpotomy, $32 \%$ permanent filling and only $8 \%$ were extraction. For group II, the percentage of each dental treatment include: $8 \%$ puplectomy, $32 \%$ pulpotomy, $44 \%$ permanent filling and $16 \%$ were extraction. For group III, the percentage of each dental treatment include: $0 \%$ puplectomy, $12 \%$ pulpotomy, $32 \%$ permanent filling and only $56 \%$ were extraction. Dentist's assessments of children accep- tance demonstrated that the treatments without difficulty were performed in $68 \%$ of children in group I and $44 \%$ of group II, meanwhile could not find in group III. The treatments with some difficulty with the help of parents holding were performed in $32 \%$ of children in group I, $56 \%$ in group II and $20 \%$ in group III.

The treatments were performed with extreme difficulty only in $80 \%$ of children in group III who did not agree to any treatment whatsoever (Figure 5). 


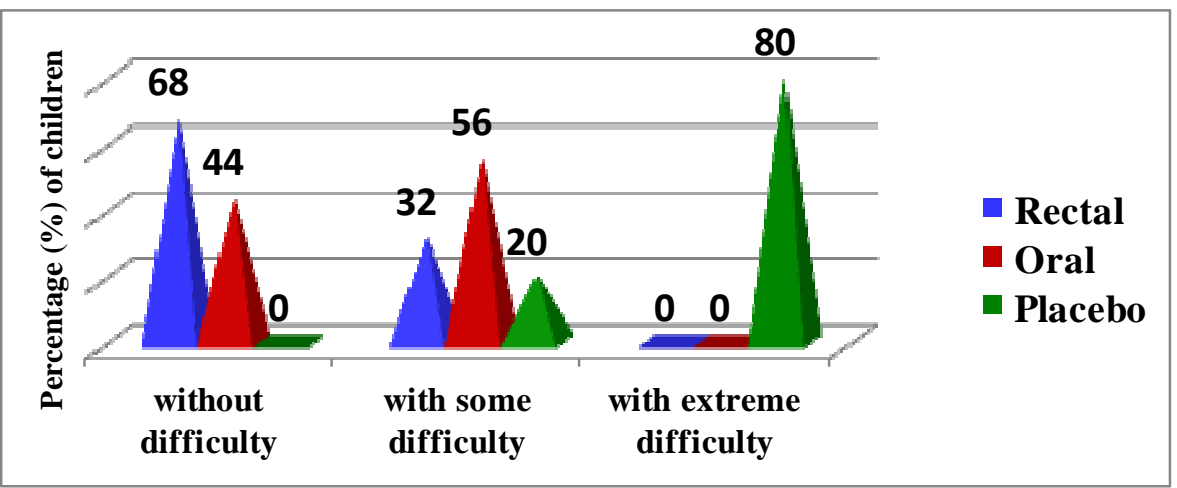

Figure (5): comparison in treatment acceptance between rectally, orally and placebo groups assessment by the dentist's.

Table (3) demonstrated the groups treatments acceptance Crosstabulation that showed that the major number of children (17) of group I treated without difficulty, the major number of children (14) of group II treated with some difficulty with the help of parents holding, meanwhile the major number of children (20) of group III treated with extreme difficulty. Pearson chi - square illustrated that the differences between groups were significant at $P \leq$ 0.05 .

Table (3): Groups $\times$ treatments acceptance Crosstabulation.

\begin{tabular}{ccccc} 
& \multicolumn{4}{c}{ Treatment acceptance } \\
Rectally & Without difficulty & With some difficulty & With extreme difficulty & Total \\
\cline { 2 - 5 } Orally & 17 & 8 & 0 & 25 \\
Placebo & 11 & 14 & 0 & 25 \\
Total & 0 & 5 & 20 & 25 \\
Pearson's chi & 28 & 27 & 20 & 75 \\
- square & Value & df & $\boldsymbol{P}$ - value & \\
\hline
\end{tabular}

*Significant difference at $P \leq 0.05$.

After one hour the dentist noticed a decreasing sedative effect of the drug but $66 \%$ of children were still sedated.

During the treatments and after 24 hours, no side - effects were reported. The parents' feeling about the treatment was
$100 \%$ satisfied and positive.

Concerning the parents' assessment of total time of sedation, $44 \%$ of parents said that their children were still sedated after 2 hours, $16 \%$ after 3 hours and $2.6 \%$ after 4 hours (Figure 6).

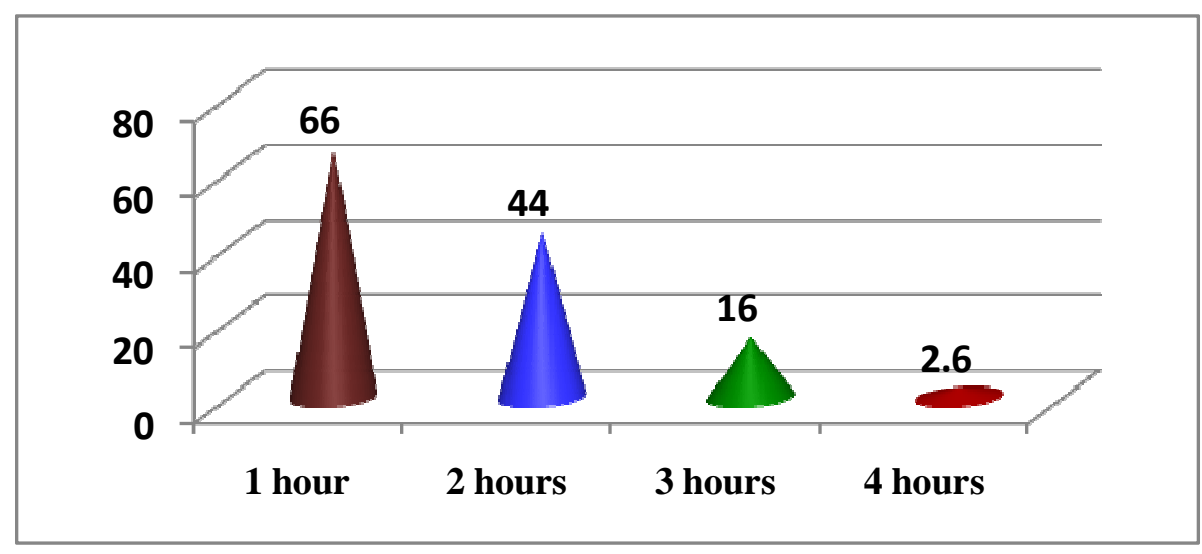

Figure (6) Parent's assessment of total time of sedation 


\section{DISCUSSION}

The most important aspects of maintaining the psychological well being of dental patients unquestionably involve the clinical management of dental fear, anxiety, and pain of treatment-factors which comprise the major deterrents to dental care. Since, dental fear and anxiety are predisposing factors toward heightening the perception of acute pain, pharmacological or behavioral therapeutic modalities that diminish dental anxiety can reasonably be expected to diminish the perceived (subjective) pain of dental procedures. The objective of any pharmacological or behavioral modality is to create a physical and psychological environment such that dental treatment can be provided with safety, comfort, and efficiency. ${ }^{(21)}$

More than 2000 benzodiazepenes have been synthesized since 1933; the most common are diazepam and midazolam. The factors that should be taken into account when using a sedative include: safety, amnesic effect, half-life, and working time. ${ }^{(11)}$

In this study the sedative effect of rectally administrated diazepam had been found to be significantly effective in management of the uncooperative children in need of dental treatments more than that of orally administrated one, meanwhile the placebo group failed to show any positive behavior improvement, that agreed with other studies ${ }^{(1,22-24)}$, even pulp therapy and restorative procedures were carried out in diazepam groups (I and II) more than in the third group in which the major dental procedures include extraction due to difficulties in children's behavior which affect the decision of treatment plan.

In this study the significantly sedative effect of rectally administrated diazepam started after 10 minutes that's agreed with other studies ${ }^{(25,26)}$ because the peak serum concentration was possibly achieved earlier after rectal administration than oral one due to the differences in the absorption characteristics occurred between the two route of administration and after using rectally diazepam solution $\left(0.7 \mathrm{mg} \mathrm{Kg}^{-1}\right)$, serum diazepam level rise fast enough within $10-20$ minutes to produce an adequate concentration of the drug within the brain, that's why in this study the onset of local anesthetic agent administration to the patient was started after 10 minutes of diazepam administration.

The degree of acceptance after premedication rectally with diazepam was very good compared to orally or placebo groups. Sixty eight percent of the sedated children accepted the planned treatments well, meanwhile thirty two percent accepted with some difficulty and with the help of the parent's preventive holding. This is well in accordance with other studies, ${ }^{\text {(22,24) }}$

In this study no adverse effects were observed at any time during or after the procedures that/s agreed with others ${ }^{(24,27)}$ and concerning total time of sedation, the sedative effect decrease after the first hour and the terminal elimination of diazepam not exceed 5 hours. This facilitates the use of it in a dental clinic. Both the dentists and the parents feel more safe when the child can leave the clinic after about one hour slightly sedated and more alert.

\section{CONCLUSIONS}

Rectally administrated diazepam resulted in a measurable sedative effect more than orally administrated one on the pediatric dental patient without a clinically detectable effect. Most of the young children were able to tolerate the single operative procedure with an increased level of cooperation.

\section{REFERENCES}

1.Jensen B, Schroder U, Mansson U. Rectal sedation with diazepam or midazolam during extractions of traumatized primary incisors: a prospective, randomized, double - blind trial in Swedish children aged $1.5-3.5$ years. Acta Odontol Scand. 1999; 57: 190 - 194.

2.Klingberg G, Berggren U, Noren JG. Dental fear in an urban Swedish child population: Prevalence and concomitant factors. Community Dent Health. 1994;11:208-14.

3.American Academy of Pediatrics. Guidelines for monitoring and management of pediatric patients during and after sedation for diagnostic and therapeutic procedures: addendum. Pediatrics. 2002;110:836-8.

4.Mason KP. The pediatric sedation service: who is appropriate to sedate, which 
medications should I use, who should prescribe the drugs, how do I bill? $P e$ diatr Radiol. 2008; 38(2): 218 - 224.

5.McCann W, Wilson S, Larsen P, Stehle $B$. The effects of nitrous oxide on behavior and physiological parameters during conscious sedation with a moderate dose of chloral hydrate and hydroxyzine. $P e$ diatr Dent. 1996;18:35-41.

6. Reeves ST, Wiedenfeld KR, Wrobleski J, Hardin CL, Pinosky ML. A randomized double-blind trial of chloral hydrate/hydrazine versus midazolam/acetaminophen in the sedation of pediatric dental outpatients. ASDC $J$ Dent Child. 1996;63:95-100.

7. Wilson S, Easton J, Lamb K, Orchardson R, Casamassimo P. A retrospective study of chloral hydrate, meperidine, hydroxyzine and midazolam regimens used to sedate children for dental care. Pediatr Dent. 2000;22:107-12.

8.Jensen B, Matsson L. Benzodiazepines in child dental care: A survey of its use among general practitioners and paediatric dentists in Sweden. Swed Dent J. 2001;25:31-8.

9. Myers GR, Maestrello CL, Mourino AP, Best AM. Effect of submucosal midazolam on behavior and physiologic response when combined with oral chloral hydrate and nitrous oxide sedation. $P e$ diatr Dent. 2004;26:37-43.

10. Abubaker AO and Benson KJ. Oral and maxillofacial surgery secrets. 2nd edition. Mosby Elsevier. Chapter 7. 2007. P. 78.

11. Tripathi KD. Essential of pharmacology for dentistry. Jaypee Brothers Medical Publishers td. 2005. Pp. 123

12. Asperheim MK. Introduction to pharmacology. Elsevier Inc. 2005. Pp.123 124.

13. Henderson BN, Triplett RG, Gage TW. Anxiolytic therapy. Oral and intravenous sedation. Dent Clin North Am. 1994;38:603-17.

14. McDonald RE, Avery DR, Dean JA. Dentistry for the child and adolescent. Mosby, Inc. 2004. Pp. 303

15. Kamienski M and Keogh J (2006) Pharmacology Demystified. The McGraw-Hill Companies, Inc. P. 128

16. van Boxtel CV, Santoso B, Edwards IR (2008) Drug Benefits and Risks: In- ternational Textbook of Clinical Pharmacology. 2nd edition. ISO, Amsterdam, Washington, DC. P. 143

17. Thorp CM (2008) Pharmacology for the Health Care Professions. John Wiley \& Sons, Ltd P. 11

18. Frankl L and Hellman I. Symposium on child analysis. The Ego's participation in the therapeutic alliance. Int $J$ Psychoanal. 1962; 43: 333 - 337.

19. Lindh U. Rectal administration of midazolam for conscious sedation of uncooperative children in need of dental treatment. Swedish Dent J. 2001; 25(3): $107-111$.

20. Wilton N, Leigh J, Rosen D, Pandit U. Preanesthetic sedation of preschool children using intranasal midazolam. Anesthesiology. 1988; 69: 972 - 975.

21. Sokol DJ, Sokol S, Sokol CK: A review of nonintrusive therapies used to deal with anxiety and pain in the dental office. J Am Dent Assoc. 1985; 110:217222.

22. Holm - Knudsen R, Clausen TG, Eno R. Rectal administration of medizolam versus diazepam for preanesthetic sedation in children. Anesth Prog. 1990; 37: $29-31$.

23. International Programme on Chemical Safety. Concise International Chemical Assessment Document no. 25. IPCS; 2000. Available from: http: //www.inchem.org/ documents/ cicads/cicads/ cicad25.htm

24. Kantovitz KR, Puppin - Rontani RM, Gaviao. Sedative effect of oral diazepam and chloral hydrate in the dental treatment of children. J Indian Soc Pedod Prev Dent. 2007; 25(2): $69-75$.

25. Knudsen FU. Plasma - diazepam in infants after rectal administration in solution and by suppository. Acta Paediat. 1977; 66: $563-567$.

26. Dhillon S, Oxlyon J, Richens A. Bioavailability of diazepam after intravenous, oral and rectal administration in adult epileptic patients. Int $J$ Pediatr Dent. 1982; 13: 427 - 432.

27. Yanase H, Braham RL, Fukuta O, Kurosu K. A study of the sedative effect of home administrated oral diazepam for the dental treatment of children. Int $J$ Pediatr Dent.1996;6:1317. 